DOI: 10.12731/2658-6649-2019-11-5-21-25

УДК 616.517: 612.017.1

\title{
ОСОБЕННОСТИ ПИЩЕВОЙ АЛЛЕРГИИ У ДЕТЕЙ С БРОНХИАЛЬНОЙ АСТМОЙ
}

Барило А.А., Борисова И.В., Смирнова С.В.

За последние годы отмечается стремительный рост распространенности бронхиальной астмы у детей с тяжельм клиническим течением заболевания. В настоящее время остается открытым вопрос о частоте и особенностях пищевой аллергии у больных БА, что обуславливает актуальность проводимого исследования. Приведены результаты исследования особенностей концентрации специифических $\operatorname{IgG4} к$ пищевым аллергенам у детей больных бронхиальной астмой. Определень особенности сенсибилизации к пищевым аллергенам при бронхиальной астме у детей.

Ключевые слова: пищевая аллергия; бронхиальная астма; аллергический ринит; аллергены.

\section{FEATURES OF FOOD ALLERGY IN CHILDREN WITH BRONCHIAL ASTHMA}

\author{
Barilo A.A., Borisova I.V., Smirnova S.V.
}

In recent years there has been a significant increase in the prevalence of bronchial asthma in children with severe clinical course of the disease. Currently, there remains an open question about the frequency and characteristics of food allergies in patients with asthma, which determines the relevance of the study. The results of the study of the peculiarities of the concentration of specific IgG4 to food allergens in children with bronchial asthma are presented. The features of food allergies in children with bronchial asthma are determined.

Keywords: food allergy; bronchial asthma; allergic rhinitis; allergens.

\section{Введение}

Бронхиальная астма (БА) является глобальной медико-социальной проблемой, актуальность изучения которой во всем мире возрастает [1]. За последние годы отмечается стремительный рост распространенности бронхиальной астмы у детей с тяжелым клиническим течением заболе- 
вания. БА представляет хроническое аллергическое воспаление бронхов, сопровождающееся их гиперреактивностью и характеризующееся периодически возникающими приступами затрудненного дыхания или удушья в результате распространенной бронхиальной обструкции, обусловленной бронхоконстрикцией, гиперсекрецией слизи, отеком стенки бронхов [2].

Респираторные проявления со стороны дыхательных путей при БА могут быть проявлением пищевой аллергии. Однако в настоящее время остается открытым вопрос о пищевой аллергии как этиологическом факторе бронхиальной астмы у детей, что обуславливает актуальность проводимого исследования [3]. Бронхиальная астма у детей чаще всего является частью так называемого «атопического марша», который характеризуется прогрессированием аллергической патологии от кожных симптомов к поражению дыхательных путей [4]. Развитие атопии детерминировано не только $\operatorname{IgE}$, но и $\operatorname{IgG} 4$-антителами [1].

\section{Цель исследования}

Изучить особенности IgG4 детерминированной сенсибилизации к пищевым аллергенам у детей больных бронхиальной астмой, проживающих на территории Красноярского края.

\section{Материалы и методы}

В исследование были включены дети, больные бронхиальной астмой $(\mathrm{n}=60)$ в возрасте от 1 года до 18 лет (средний возраст $-7,5 \pm 0,6$ лет) с интермиттирующей и легкой персистирующей формами заболевания. Средняя продолжительность заболевания составила $3,0 \pm 0,5$ лет. Среди обследованных детей больных бронхиальной астмой преобладали мальчики $63,3 \%$ (38).

Проведено определение концентрации специфических IgG4 к $\alpha$-лактоглобулине, $\beta$-лактоглобулине, казеине, бычьему сывороточному альбумину, овальбумину, глиадину методом иммуноферментного анализа с использованием аллергопанели Allergopharma (Германия). Критерием сенсибилизации считали повышение уровня специфического IgG4 выше порогового согласно инструкции производителя: более 0,25 MЕ/мл для $\alpha$-лактоглобулине и бычьего сывороточного альбумина, более $0,70 \mathrm{ME} /$ мл для казеина, более $0,56 \mathrm{ME} /$ мл для овальбумина, более 0,21 для $\beta$-лактоглобулина, МЕ/мл более 0,15 МЕ/мл для глиадина. Для статистического анализа применяли пакет прикладных программ Statistica 6,0. Статистическую обработку данных проводили методами вариационного анализа с 
использованием t-критерия для качественных признаков. Различия считались статистически достоверным при $\mathrm{p}<0,05$.

\section{Результаты и обсуждение}

Выявлено, что у 63,3\% (38) детей бронхиальная астма сочеталась с проявлениями круглогодичного аллергического ринита - единая болезнь респираторного тракта (one way, one disease, allergic rhinobronchitis, ARIA, 2001). У больных бронхиальной астмой в $25,6 \%$ (16) случаев отмечены проявления сезонного аллергического ринита и в 8,3\% (6) - сезонного аллергического риноконъюнктивита.

В проведенном нами исследовании повышенный уровень специфических IgG4 выявлен у 88,3\% (53) больных. При изучении спектра пищевой сенсибилизации определено, что чаще всего отмечена сенсибилизация к овальбумину $-81,2 \%$ (43) и $\beta$-лактоглобулину - 75,5\% (40) случаев. IgG4 детерминированная сенсибилизация определена к бычьему сывороточному альбумину и $\alpha$-лактоглобулину в $69,8 \%$ (37), глиадину в $67,9 \%$ (36), и казеину в 43,4\% (23) случаев.

Частота поливалентной сенсибилизации к белкам коровьего молока, яиц, злакам выявлена у 79,2\% (42) больных бронхиальной астмой, бивалентной сенсибилизации - в 9,4\% (5) случаев, моновалентной сенсибилизации - в 11,3\% (6) случаев. При моновалентной сенсибилизации среди пищевых аллергенов отмечены белки коровьего молока - 50,0\% (3) случаев, овальбумин - 33,3\% (2), глиадин - 16,7\% (1).

\section{Заключение}

Таким образом, проведенные исследования позволяют проанализировать спектp IgG4 детерминированной сенсибилизации к специфическим пищевым аллергенам при бронхиальной астме у детей и выявить определенные закономерности. Установлено, что наиболее значимым пищевыми аллергенами у детей больных бронхиальной астмой является овальбумин, бычий сывороточный альбумин, $\alpha$-лактоглобулин и глиадин. В меньшей степени при бронхиальной астме определяется IgG4 детерминированная сенсибилизация к казеину. В подавляющем большинстве случаев при бронхиальной астме определена поливалентная сенсибилизация к пищевым аллергенам.

\section{Список литературы}

1. Sherenian M.G., Singh A.M., Arguelles L., Balmert L., Caruso D., Wang X., Pongracic J., Kumar R. Association of food allergy and decreased lung func- 
tion in children and young adults with asthma // Ann Allergy Asthma Immunol. 2018; 121:588-93.

2. Borisova I.V., Smirnova S.V. The peculiarities of food allergies in accordance with the level of injury of respiratory tract in children of Eastern Siberia // Intetnathional Journal of Circumpolar Health. 2013; 72 (1):301-304.

3. Борисова И.В., Смирнова С.В. Пищевая аллергия у детей. Красноярск, 2011, $150 \mathrm{c}$.

4. Барило А.А., Борисова И.В., Смирнова С.В. Дерматореспираторный синдром как проявление пищевой аллергии у детей // Российский аллергологический журнал. 2019; 16 (1-2): 32-32.

\section{References}

1. Sherenian M.G., Singh A.M., Arguelles L., Balmert L., Caruso D., Wang X., Pongracic J., Kumar R. Association of food allergy and decreased lung function in children and young adults with asthma. Ann Allergy Asthma Immunol. 2018; 121:588-93.

2. Borisova I.V., Smirnova S.V. The peculiarities of food allergies in accordance with the level of injury of respiratory tract in children of Eastern Siberia. International Journal of Circumpolar Health. 2013; 72 (1):301-304.

3. Borisova I.V., Smirnova S.V. Pishchevaya allergiya u detej [Food allergy in children]. Krasnoyarsk, 2011, 150 p.

4. Barilo A.A., Borisova I.V., Smirnova S.V. Dermatorespiratornyj sindrom kak proyavlenie pishchevoj allergii u detej [The dermato-respiratory syndrome as a manifestation of food allergy in children.]. Rossijskij allergologicheskij zhurnal [Russian Allergology Journal]. 2019; 16 (1-2): 32-32.

\section{ДАННЫЕ ОБ АВТОРАХ}

Барило Анна Александровна, к.м.н., старший научный сотрудник лаборатории клинической патофизиологии

Научно-исследовательский институт медицинских проблем Севера - обособленного подразделения ФИЦ КНЦ СО РАН

ул. Партизана Железняка, 32, г. Красноярск, 660022, Российская Федерация

anntomsk@yandex.ru

Борисова Ирина Васильевна, к.м.н., врач аллерголог-иммунолог Клиника «Доктор» ул. 78 Добровольческой бригады, 21, г. Красноярск, 660022, Российская Федерация krasdoctor@yandex.ru 
Смирнова Светлана Витальевна, д.м.н., профессор, руководитель научного направления

Научно-исследовательский институт медицинских проблем Севера - обособленного подразделения ФИЦ КНЦ СО РАН

ул. Партизана Железняка, 32, г. Красноярск, 660022, Российская Федераиия

svetvita@mail.ru

\section{DATA ABOUT THE AUTHORS}

Barilo Anna Aleksandrovna, $\mathrm{PhD}$, Researcher of the Clinical Pathophysiology Laboratory

Research Institute of Medical Problems of the North - a separate division of the FIC KSC SB RAS

3g, Partizan Zheleznyak Str., 660022, Krasnoyarsk, Russian Federation anntomsk@yandex.ru

Borisova Irina Vasilevna, $\mathrm{PhD}$, allergist-immunologist

Clinic "Doctor"

21, 78 Dobrovol'cheskaya brigada Str., Krasnoyarsk, 660022, Russian Federation

krasdoctor@yandex.ru

Smirnova Svetlana Vitalevna, PhD, Professor, Head of the Scientific Direction Research Institute of Medical Problems of the North - a separate division of the FIC KSC SB RAS

3g, Partizan Zheleznyak Str., 660022, Krasnoyarsk, Russian Federation svetvita@mail.ru 